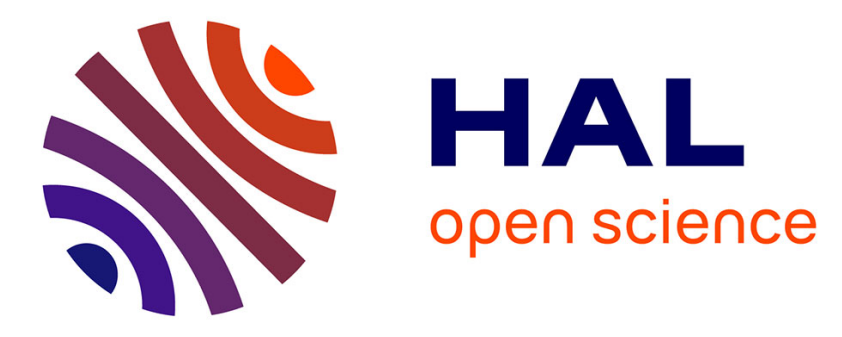

\title{
Spin-driven activation of dioxygen in various metalloenzymes and their inspired models.
}

\author{
Aurelien de La Lande, Dennis R Salahub, Jacques Maddaluno, Anthony \\ Scemama, Julien Pilme, Olivier Parisel, Helene Gerard, Michel Caffarel, \\ Jean-Philip Piquemal
}

\section{To cite this version:}

Aurelien de La Lande, Dennis R Salahub, Jacques Maddaluno, Anthony Scemama, Julien Pilme, et al.. Spin-driven activation of dioxygen in various metalloenzymes and their inspired models.. Journal of Computational Chemistry, 2011, 32 (6), pp.1178-1182. 10.1002/jcc.21698 . hal-00992047

\section{HAL Id: hal-00992047 https://hal.science/hal-00992047}

Submitted on 29 Jan 2020

HAL is a multi-disciplinary open access archive for the deposit and dissemination of scientific research documents, whether they are published or not. The documents may come from teaching and research institutions in France or abroad, or from public or private research centers.
L'archive ouverte pluridisciplinaire $\mathbf{H A L}$, est destinée au dépôt et à la diffusion de documents scientifiques de niveau recherche, publiés ou non, émanant des établissements d'enseignement et de recherche français ou étrangers, des laboratoires publics ou privés. 


\title{
Spin-driven activation of dioxygen in various metalloenzymes and their inspired models
}

\author{
Aurélien de la Lande ${ }^{1,2 *}$ Dennis R. Salahub, ${ }^{1}$ Jacques Maddaluno, ${ }^{3}$ Anthony Scemama, ${ }^{4}$ Julien \\ Pilmé, ${ }^{5,6,}$ Olivier Parisel, ${ }^{6,}$ Hélène Gérard, ${ }^{6,}$ Michel Caffarel, ${ }^{4}$ and Jean-Philip Piquemal ${ }^{6, *}$
}

The need for green, profitable, and highly selective catalytic processes is becoming increasingly acute. When targeting oxygenation and/or oxidation of saturated compounds, one appealing route is to employ molecular oxygen, a readily available chemical, as the oxidant. In his ground state free dioxygen molecule is however a spin-polarized triplet and as such is inert toward substrate oxidation. On the other hand, the singlet states are more much reactive even if they in general lie higher in energy. Catalysts are thus required to promote the spin-forbidden triplet to singlet transition to use dioxygen as an oxidizing agent. This strategy has proven to be very promising for palladium-catalyzed aerobic oxidation, for example. ${ }^{i}$ More generally, this approach is legitimized by the ubiquity of metalloenzymes in aerobic life that activate dioxygen and exploit its oxidative power. ${ }^{\text {ii }}$ Numerous studies have been undertaken in the last decades to understand the underlying mechanisms leading to $\mathrm{O}_{2}$ activation. One of the most remarkable lessons has been the identification of a broad range of chemical strategies that enzymes may follow to produce the oxidative species they need, depending on their particular chemical structure. In the recent past, a seemingly simple strategy has emerged from biochemical studies. Various enzymes have been found to make direct use of metal-dioxygen adducts $\left(\mathrm{M}_{\mathrm{n}} \mathrm{O}_{2}\right)$ to oxidize their substrates. Within such

adducts, and depending on the chemical nature of the active site, the dioxygen moiety generally undergoes a partial reduction towards a superoxide $\left(\mathrm{O}_{2}{ }^{-\bullet}\right)$ or a peroxide $\left(\mathrm{O}_{2}{ }^{2-}\right)$ form. Among the enzymes that use this strategy, Tyrosinase (Tyr), ${ }^{3}$ Catechol Oxidase (CO), ${ }^{\text {iii }}$ Tyramine $\beta$-Monooxygenase $(\mathrm{T} \beta \mathrm{M}),{ }^{\mathrm{iv}}$ Peptidylglycine $\alpha$ Hydroxylating Monooxygenase (PHM), and Dopamine $\beta$ Hydroxylase $(D \beta M)^{v, v i}$ are six ubiquitous cuproenzymes involved respectively in the metabolism of phenols, tyramine, neuropeptides and neurotransmitters. Some non-haem iron enzymes have also been identified, like the Extradiol Dioxygenases (EXD) that initiate the degradation of many aromatic compounds in bacteria. ${ }^{\text {vii }}$ In addition to biochemical studies, several attempts have been made to synthesize metal-dioxygen adducts $\mathrm{M}_{\mathrm{n}} \mathrm{O}_{2}$ using, for example, copper, ${ }^{\text {viii,ix }}{ }^{2}$ iron, ${ }^{\mathrm{x}}$ nickel, ${ }^{\mathrm{xi}, \mathrm{xii}}$ or palladium ${ }^{\mathrm{xiii}}$ complexes. However, despite notable successes in the preparation and characterization of

[1] Department of Chemistry and Institute for Biocomplexity and Informatics, University of Calgary, 2500 University Drive NW, Calgary, Alberta, Canada. T2N 1N4.

[2] Laboratoire de Chimie Physique, Université Paris-Sud 11. Bât. 349, Campus d'Orsay. 15, rue, Georges Clémenceau. 91405 Orsay Cedex. France

[3] CNRS UMR 6014 \& FR 3038, IRCOF, Université de Rouen, F. 76821 Mont Saint Aignan Cedex, France.

[4] Laboratoire de Chimie et Physique Quantiques, CNRS-UMR 5626, IRSAMC Université de Toulouse, 118 route de Narbonne, 31062 Toulouse Cedex, France

[5] Faculté de pharmacie, Université Lyon 1, F. 69373 Lyon Cedex 08, France.
[6] Laboratoire de Chimie Théorique, UPMC - Paris 6, UMR 7616 CNRS, CC 137, 4 place Jussieu, F. 75252 Paris Cedex 05, France.

*Corresponding authors: AL (ORSAY): aurelien.de-la-lande@u-psud.fr JPP (UPMC): jpp@lct.jussieu.fr

Supporting information for this article is available on the WWW

such species, it has been most of the time difficult to use them for subsequent oxidative reactions. Although detailed molecular orbital studies have been devoted to these systems for a long time, ${ }^{x i v, x v, x v i}$ the electronic properties of such complexes are not totally understood. Among the electronic aspects to be addressed for oxygen complexes, the spin state certainly plays a major role. Besides a high-spin complex formed upon direct coordination of triplet dioxygen to the metal centre, the resulting adduct can also adopt various low-lying spin states. Actually, for a given system, it is hard to predict which spin state is the most reactive. These states are generally close in energy and slight variations within the coordination spheres of the metal ions (chemical composition or spatial arrangement of the ligands) can change the relative stabilities.

In this report, we provide an unprecedented description of the electronic properties of such adducts based on state-of-the-art calculations. Five inorganic complexes were retained which are representative of the various strategies followed by enzymes to produce reactive $\mathrm{M}_{\mathrm{n}} \mathrm{O}_{2}$ adducts (Figure 1). The topological analysis of the Electron Localization Function $(E L F)^{\text {xvii,xviii }}$ coupled to Density Functional Theory (DFT) provides a powerful way to elucidate the electronic structures of molecules of biological interest (See Methods Section). ${ }^{\text {xix }}$ It is applied here to trace the shape of the electron pair density around the oxygen atoms within $\mathrm{M}_{\mathrm{n}} \mathrm{O}_{2}$ complexes, which is shown to be connected to the spin multiplicity of the adducts. We suggest that enzymes could resort to spin state control to tune the regioselectivity of substrate oxidations.

We began this study with the binuclear copper complex $\left[(\mathrm{ImH})_{6} \mathrm{Cu}_{2}\left(\mathrm{O}_{2}\right)\right]^{2+}$ which is an adequate model of the active sites of Tyrosinase ${ }^{\mathrm{xx}}$ and Catechol oxidases. It contains a $\mathrm{Cu}_{2} /\left(\mu-\eta^{2}: \eta^{2}-\mathrm{O}_{2}\right)$ core with an unusual organization consisting of a three-centre $\mathrm{Cu}-\mathrm{O}-$ $\mathrm{Cu}$ bond. ${ }^{\mathrm{xxi}}$ The second adduct, $\left[\left(\mathrm{Mim}^{\mathrm{N} 2 \mathrm{~S}}\right) \mathrm{Cu}\left(\mathrm{O}_{2}\right)\right]^{+}$, is a biomimicking model of the $\mathrm{Cu}_{\mathrm{M}}$ active site found in the non-coupled dicopper enzymes PHM, D $\beta M$, and $T \beta M$. . $^{\text {xii }}$ These systems have been studied in their singlet and triplet spin states through extensive use of Molecular Orbitals (MO), see for example ref xxiii. The ELF isosurfaces (Figure 2) reveal a particular spatial polarization of the valence basins $\mathrm{V}(\mathrm{O})$ related to the oxygen atoms. Such basins, which cannot be distinguish when looking at MOs, are identified with the oxygen lone pairs, keeping in mind that such non-bonding densities are considered here in a larger picture that in the usual formal Lewis theory: an ELF lone pair can hold an electronic population larger than 2 (Table 1). Interestingly, a particular spatial orientation of these $\mathrm{V}(\mathrm{O})$ basins is found to be spin-dependent. They are included within the $\mathrm{Cu}_{(2)} \mathrm{O}_{2}$ plane in the case of the triplet adducts but are perpendicular to it for the singlet adducts. In other words, a $90^{\circ}$ rotation of the dioxygen lone pairs is observed, as 
confirmed by the values of the $\mathrm{Cu}-\mathrm{O}-\mathrm{O}-\mathrm{V}(\mathrm{O})$ dihedral angles gathered in Table 1. It is worth mentioning that similar patterns are

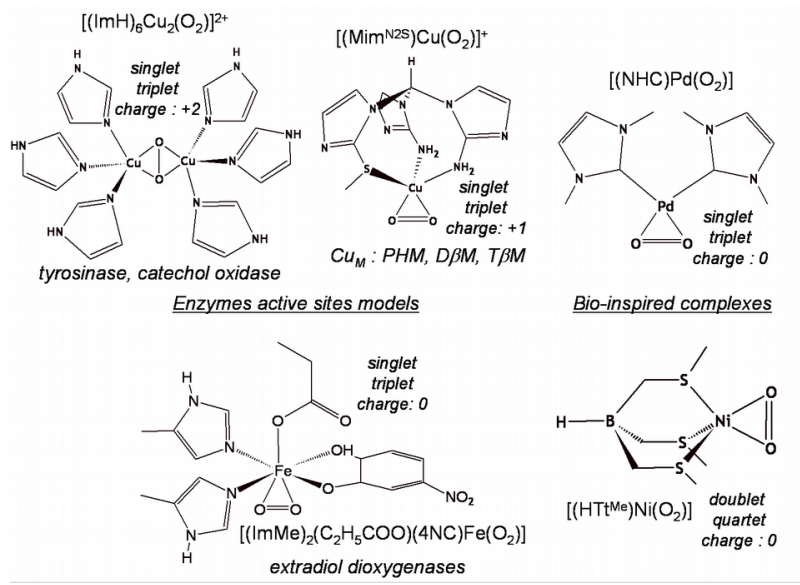

recovered for the $\mathrm{Cu}_{2} /\left(\mu-\eta^{2}\right.$ : $\left.\eta^{2} \mathrm{O}_{2}{ }^{2}\right)$ singlet core using alternative approaches such as the topological analysis of the electrostatic potential, ${ }^{\text {xiv }}$ or the direct statistical sampling of the electron positions obtained by means of Quantum Monte-Carlo (QMC) based electron pair localization function schemes (see Supp. Mat.), attesting thus to the robustness of the observed ELF patterns. ${ }^{\mathrm{xxv}, \mathrm{xxvi}}$

Figure 1. Chemical structures of the five complexes investigated in this study with their total charge and the spin states considered.
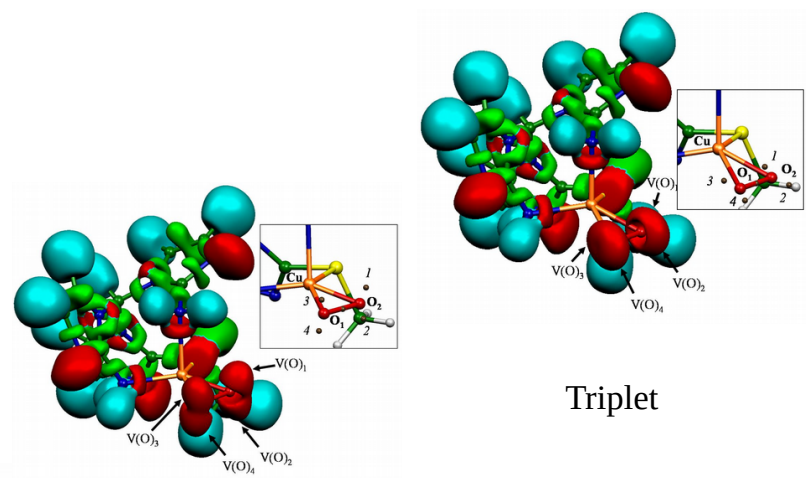

Triplet
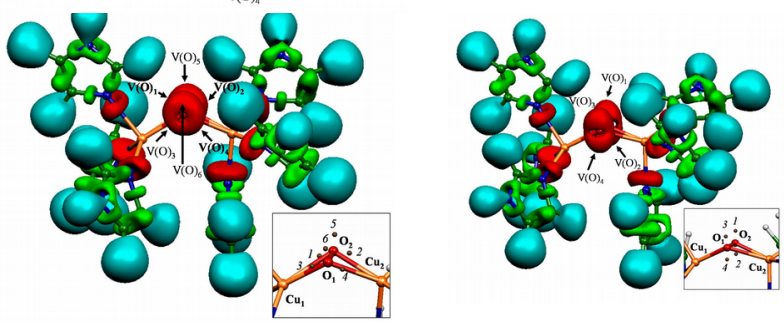

Figure 2. ELF isosurfaces $(\eta=0.8)$ of the $\left[\left(\mathrm{MimN}_{2} \mathrm{~S}\right) \mathrm{Cu}\left(\mathrm{O}_{2}\right)\right]^{+}$(top) and $\left[(\mathrm{ImH})_{6} \mathrm{Cu}_{2}\left(\mathrm{O}_{2}\right)\right]^{2+}$ (bottom) adducts in their singlet and triplet states. The insets on the $\mathrm{Cu}_{(2)} \mathrm{O}_{2}$ core highlight the attractor positions of the oxygen basins. Basin colour code: red for non-bonding (lone pair), green for bonding and light blue for protonated bond. The difference in the basin orientations seems less eye-catching in the Tyr case due to the appearance of two extra lone pair attractors $\left(\mathrm{V}_{5}\right.$ and $\left.\mathrm{V}_{6}\right)$ at the $\mathrm{Cu}_{2} \mathrm{O}_{2}$ core caused by a more pronounced butterfly effect. The rotation is however evident in view of the position of the attractors (inset and Table 1).
As for the $\mathrm{Cu}-\mathrm{O}-\mathrm{O}-\mathrm{V}(\mathrm{O})$ angles, the volumes of the valence oxygen basins also appear to be spin dependent and thus offer some complementary quantitative elements. Overall, the oxygen lone pairs contain mostly the same total number of electrons in both spin states. On the other hand, their spatial extensions, and hence their accessibility for an exogenous substrate, are different. In the singlet states, the two valence basins at one oxygen exhibit equal volumes, leading to similar electronic expansion on the two sides of the $\mathrm{Cu}_{(2)} \mathrm{O}_{2}$ averaged plane. In contrast, in the triplet state, the different basins exhibit very different volumes, the basins lying between copper and oxygen being much smaller than those lying on the outside.

Following the study of mono and dinuclear copper centres, similar spin-dependencies are found for the $\left[\left(\mathrm{HTt}^{\mathrm{Me}}\right) \mathrm{Ni}\left(\mathrm{O}_{2}\right)\right]$, $\left[(\mathrm{NHC})_{2} \mathrm{Pd}\left(\mathrm{O}_{2}\right)\right]$, and $\left[(\mathrm{ImMe})_{2}\left(\mathrm{C}_{2} \mathrm{H}_{5} \mathrm{COO}\right)(4 \mathrm{NC}) \mathrm{Fe}\left(\mathrm{O}_{2}\right)\right]$ adducts, although different spin states are to be considered depending on the nature of the metal ion (see Supp. Information.). This is, for example, the case for the nickel complex which is associated with either a doublet or a quartet state. Strikingly, the rotation of the dioxygen lone pairs appears to be a shared characteristic of $\mathrm{M}_{\mathrm{n}} \mathrm{O}_{2}$ complexes.

A rationalization of these trends is achievable using a $\mathrm{MO}$ analysis of the complexes. Upon interaction with a metallic complex, the dioxygen $\pi_{\mathrm{x}}{ }^{*}$ antibonding MO undergoes a mixing with a symmetry-adapted $\mathbf{d}$ orbital of the metal ion, whereas the $\pi_{\mathrm{y}}{ }^{*}$ $\mathrm{MO}$, interacting in $\delta$ symmetry with the metal, is generally considered as unperturbed. This is evidenced in Figure 3 in the case of $\left[\left(\mathrm{Mim}^{\mathrm{N} 2 \mathrm{~S}}\right) \mathrm{Cu}\left(\mathrm{O}_{2}\right)\right]^{+}$, an adduct relevant to the $\mathrm{Cu}_{\mathrm{M}}$ centre of PHM, $\mathrm{D} \beta \mathrm{M}$, and $\mathrm{T} \beta \mathrm{M}$.

As the symmetries of the dioxygen $\pi$ and $\pi^{*}$ orbitals match those observed for the dioxygen lone pairs (Figure 2), the respective occupations of the MOs can be connected to the topology of the ELF basins. In the case of a closed-shell singlet configuration $(1)^{2}(2)^{0}$, the symmetry of the dioxygen valence basins is obtained by superimposing the three electron pairs at the oxygen, namely the two dioxygen $\pi^{*}$ orbitals (resulting in a cylindrical symmetry) and the dioxygen lowest energy MO 1, i.e. $\pi_{\mathrm{y}}{ }^{*}$ : the resulting basin will thus be mostly oriented along the y direction, namely, perpendicular to the $\mathrm{CuO}_{2}$ plane. In the triplet configuration $(1)^{1}(2)^{1}$, no electron pairing can result from the singly occupied $\pi^{*}$ system and the resulting orientation of the $\mathrm{V}(\mathrm{O})$ basins reflects the small participation of $\pi_{x}{ }^{*}$ to the mostly metal centred $d_{x z} / \pi_{x}{ }^{*}$ bonding orbital (Figure 3, bottom orbital), which justifies both the small polarization and the alternative symmetry with respect to the singlet system.

This suggests a possible relationship between the spin density of the $\mathrm{M}_{\mathrm{n}} \mathrm{O}_{2}$ core and the topology of the ELF function. This hypothesis is tested more in depth using the introduced numerical constrainedDFT (CDFT) approach ${ }^{\text {xxvii,xxviii }}$ consisting of the progressive reduction by one electron of the previous singlet complex together with the examination of the evolution of the ELF basins (Figure 3). To this end, a remote hydrogen atom, the electronic charge of which is constrained, acts as the reductive species (see Methods section). Starting from a total charge of +1 on the complex and a low-spin density on the $\mathrm{CuO}_{2}$ core, the successive injections of fractions of an electron to the complex leads to a progressive reduction of the $\mathrm{CuO}_{1} \mathrm{O}_{2} \mathrm{~V}(\mathrm{O})_{1 / 3}$ angles and to the increase of the $\mathrm{V}(\mathrm{O})_{2 / 4}$ basin volumes. Three main conclusions can be drawn from this numerical experiment. First, it confirms the previous MO analysis stating that the respective populations of the frontier orbitals (that generate the two limit symmetries) determine the symmetry of the ELF basins. 
Second, these results account for the changes of symmetry described above regarding the adduct spin state, as the singlet and the triplet states involve different populations of the MOs. Finally it shows that symmetry does not change sharply but rather smoothly upon variation of the $\pi^{*}$ orbital populations. This latter point implies that intermediate situations with particular spatial polarization and extensions of the oxygen lone pairs are, in principle, possible. In biological or bio-inspired systems, the electron reservoir currently used in the CDFT computation could consist in protein residues, enzymatic substrates or organic substituents. This hypothesis is examined in the discussion part, altogether with an analysis of the control of the bio-inspired oxidation reactions relying on the orientation patterns described above.

\begin{tabular}{llllll} 
& & \multicolumn{2}{c}{$\left[\left(\mathrm{Mim}^{\mathrm{N} 2 \mathrm{~S}}\right) \mathrm{Cu}\left(\mathrm{O}_{2}\right)\right]^{+}$} & \multicolumn{2}{l}{$\left[(\mathrm{ImH})_{6} \mathrm{Cu}_{2}\left(\mathrm{O}_{2}\right)\right]^{2+}$} \\
& & singlet & triplet & singlet & Triplet \\
\hline$\Delta \mathrm{E}$ & & -2.2 & 0.0 & -3.8 & 0.0 \\
\hline Dih. & $\mathrm{Cu}_{(1)} \mathrm{O}_{1} \mathrm{O}_{2} \mathrm{~V}(\mathrm{O})_{1 / 3}$ & 95.4 & 2.5 & 114.3 & 12.1 \\
angle & $\mathrm{Cu}_{(1)} \mathrm{O}_{1} \mathrm{O}_{2} \mathrm{~V}(\mathrm{O})_{2 / 4}$ & -93.1 & -176.2 & -67.2 & -134.8 \\
& $\mathrm{~V}(\mathrm{O})_{1}$ & $54.5 / 2.90$ & $26.1 / 2.06$ & $51.3 / 2.97$ & $32.6 / 2.09$ \\
$\mathrm{Vol} . /$ & $\mathrm{V}(\mathrm{O})_{2}$ & $53.2 / 2.93$ & $76.7 / 3.56$ & $42.0 / 3.10$ & $15.2 / 1.39$ \\
$\mathrm{~N}_{\mathrm{e}-}$ & $\mathrm{V}(\mathrm{O})_{3}$ & $57.0 / 2.92$ & $35.9 / 2.32$ & $48.8 / 3.00$ & $16.2 / 1.43$ \\
& $\mathrm{~V}(\mathrm{O})_{4}$ & $58.2 / 2.92$ & $74.4 / 3.28$ & $42.1 / 3.12$ & $30.1 / 2.06$ \\
& $\mathrm{~V}(\mathrm{O})_{5}$ & - & - & - & $44.7 / 2.56$ \\
& $\mathrm{~V}(\mathrm{O})_{6}$ & - & - & - & $43.6 / 2.60$
\end{tabular}

Table 1: Positions and characteristics (volume/population) of the valence attractors of the oxygen atoms in the $\left[\left(\mathrm{Mim}^{\mathrm{N2S}}\right) \mathrm{Cu}\left(\mathrm{O}_{2}\right)\right]^{+}$and $\left[(\mathrm{ImH})_{6} \mathrm{Cu}_{2}\left(\mathrm{O}_{2}\right)\right]^{2+}$ complexes (the numbering is defined on Figure 2). The dihedral angles are given in degrees and the $\mathrm{V}(\mathrm{O})$ volumes in $\AA^{3}$. The integrated electron density over the basin volumes $\left(\mathrm{N}_{\mathrm{e}}\right)$ is unitless. The Singlet-triplet gaps (in $\mathrm{kcal} / \mathrm{mol}$ ), extracted from references Error: Reference source not found and ${ }^{\text {xxix }}$, were computed with a spin-flip TD-DFT.
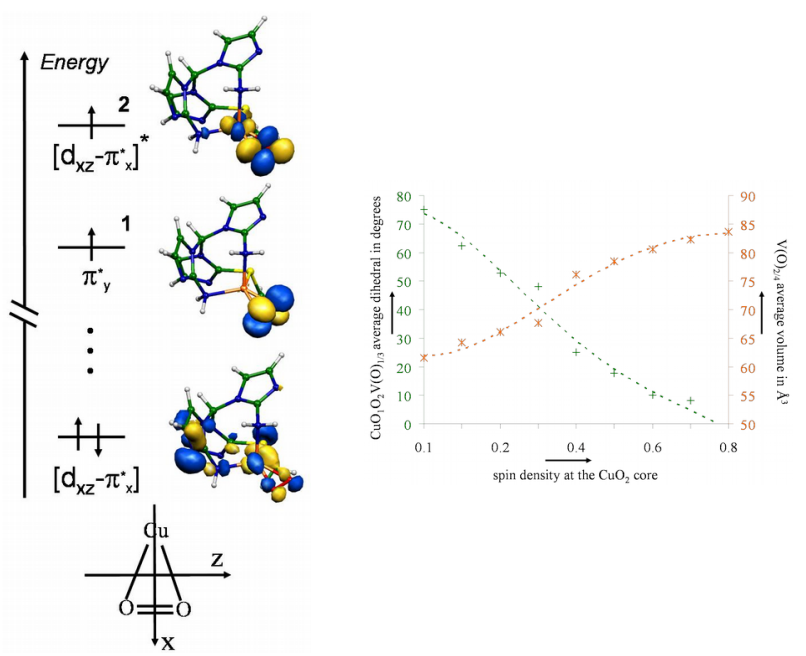

Figure 3. Left: MOs resulting from the interaction between the dioxygen $\pi_{x}^{*}$ and $\pi_{y}^{*}$ molecular orbitals and the copper $d_{x z}$ orbital for the case of the $\left[\left(\mathrm{Mim}^{\mathrm{N} 2 \mathrm{~S}}\right) \mathrm{Cu}\left(\mathrm{O}_{2}\right)\right]^{+}$complex. Right: evolution of the average $\mathrm{CuO}_{1} \mathrm{O}_{2} \mathrm{~V}(\mathrm{O})_{1 / 3}$ dihedral angles as a function of the spin density at the $\mathrm{CuO}_{2}$ core upon progressive injection of one electron (constrained DFT computations) at a frozen geometry.

The information gathered on copper and non-heam iron enzymes provides the first pieces of an answer. The architecture of the Tyr and CO active sites implies that the approach of an exogenous substrate necessarily occurs along a path out of the average $\mathrm{Cu}_{2} \mathrm{O}_{2}$ plane. ${ }^{\mathrm{xxx}}$ Thus, a successful reaction is likely to occur with singlet adducts exhibiting an appropriate directionality of their electron pair densities, i.e. out of the $\mathrm{Cu}_{2} \mathrm{O}_{2}$ plane. In contrast, the triplet reaction pathway should be less efficient due to both the orientation of the lone pairs and their reduced spatial extension out of the $\mathrm{Cu}_{2} \mathrm{O}_{2}$ plane. Because the mononuclear copper centres of PHM, D $\beta M$ and T $\beta M$ give more flexibility to their substrates when approaching the $\mathrm{Cu}_{\mathrm{M}} \mathrm{O}_{2}$ adduct, the interpretation of the oxidative properties of these active sites is less straightforward and is probably controlled by the specific docking sites in the enzymes. The most recent studiesError: Reference source not found ${ }^{\text {xxxi,xxxii }}$ indicate that the substrate oxidation is promoted by a formal $\left[\mathrm{Cu}_{\mathrm{M}}(\mathrm{II})\left(\mathrm{O}_{2}\right)^{\bullet}\right]$ adduct that formally grabs a hydrogen atom or an hydride from one of the substrate's $\mathrm{C}-\mathrm{H}$ bonds. ${ }^{\text {xxxiii }}$ The X-Ray structures of the PHM enzyme, ${ }^{\text {xxiv, }, x x x}$ show a constant docking of the substrate with respect to the $\mathrm{Cu}_{\mathrm{M}}$ site suggesting a non-fortuitous orientation of all interacting intervening molecules.The last enzymatic example is the family of non-heam iron extradiol ring-cleaving dioxygenases. Recent X-Ray structures have brought decisive information about their catalytic mechanisms.Error: Reference source not found Using a slow aromatic substrate (4-Nitrocatechol, 4NC), it has been possible to trap an intermediate in which the dioxygen moiety is partly reduced to a superoxide radical, coordinated to a Fe(II) cation (Figure 1). The substrate is assumed to be a radical so that the overall structure can be described as a biradical. ${ }^{\text {xxvi }}$ In the subsequent step, a radical combination occurs between the two previous fragments, leading to an alkylperoxo intermediate. The crystal characterization of this latter has been reported for the first time in the same study. Our DFT computation on the $\left[(\mathrm{ImMe})_{2}\left(\mathrm{C}_{2} \mathrm{H}_{5} \mathrm{COO}\right)(4 \mathrm{NC}) \mathrm{Fe}\left(\mathrm{O}_{2}\right)\right]$ model fully supports the authors' conclusions. Two spin states have been considered, singlet and triplet, which show different lone pair polarizations as mentioned above. It is worth stressing that for the biradical singlet (DFT broken symmetry), only three ELF attractors are found, corresponding to oxygen monosynaptic valence basins. No monosynaptic valence basin attractors are present in front of the substrate's carbon atom that is covalently linked to the oxygen atom in the subsequent intermediate. In contrast, all the electron density corresponding to the lone pairs is expelled out of this region into a common basin that holds 5.7 electrons (See Supp. Information). A successful radical recombination should indeed involve low ELFvalue regions that correspond to high probabilities of finding unpaired electrons. In such conditions, the respective positions of the substrate and the oxygen lone pairs appear to be remarkably suited for the reaction to proceed. The cases of the bio-inspired nickel and palladium complexes are less documented, even though efficient catalysis has already been reported using palladium adducts.Error: Reference source not found

As suggested above a fine-tuning of the substrate docking may permit regioselective catalysis thanks to the spin-dependent topology of the electron pair density around the oxygen moieties. Future studies taking into account the full enzymatic environment through hybrid QM/MM computations and dynamical effects will have to confirm this hypothesis derived from in vacuo computations. From the view point of enzymologic perspectives such behaviours are however likely to be key elements in the understanding dioxygen activation rules for instance in the framework of the NAC (Near 
Attack Conformers) theory ${ }^{\mathrm{xx} x \mathrm{ii}}$ or related approaches (see ref [ [xxviii] for a detailed review).

Details about theoretical procedures are available in the Supporting Information.

Abbreviations: NHC: N-heterocyclic carbenes.; $\mathrm{HTt}^{\mathrm{Me}}$ : (tris(methylthio)methyl)hydroborate.; ImH: imidazole.; ImMe: methylimidazole.; 4NC: 4-Nitrocatechol

S. S. Stahl, Science, 2005, 309, 1824.

L. Jr Que, W. B. Tolman, Nature, 2008, 455, 333.

B. F. Gherman, C. J. Cramer, 2009, 253, 723.

E. E. Gray, S. N. Small, M. A. McGuirl, Prot. Exp. Purif., 2006, 47, 162.

J. P.Klinman, J. Biol. Chem. 2006, 281, 3013.

A. de la Lande, O. Parisel, H. Gérard, V. Moliner, O.Reinaud, Chem. Eur. J. 2008, 14, 6465.

vii J. D. Lipscomb, E. G. Kovaleva, Science 2007, 316, 453.

viii $\quad$ E. A. Lewis, W. B. Tolman, Chem. Rev., 2004, 104, 1047

C. J. Cramer, W. B. Tolman, Acc. Chem. Res., 2007, 40, 601.

M. Costas, M.P. Mehn, M. P. Jensen, L. Jr Que, Chem. Rev. 2004,

104, 939.

xi K. Fujita, R. Schenker, W. Gu, T. C. Brunold, S. P. Cramer, C. G. Riordan, Inorg. Chem., 2004, 43, 3324.

xii $\quad$ Cho J., Sarangi, R., Annaraj, J., Kim, S. Y., Kubo, M., Ogura, T., Solomon, E. I. Nam, W. Nat. Chem. 2009, 1, 568.

xiii B. V. Popp, J. E. Wendlandt, C. R. Landis, S; S. Stahl, Angew. Chem. Int. Ed. 2007, 46, 601.

${ }^{\text {xiv }}$ P. Chen, E. I. Solomon, J. Inorg. Biochem, 2002, 88, 368.

${ }^{x v}$ E. I. Solomon, P. Chen, M., Metz, S.-L. Lee, A. E. Palmer, Angew. Chem. Int. Ed. 2001, 40, 4570.

${ }^{\text {xvi }}$ C. J. Cramer, J. R. Gour, A. Kinal, M. Włoch, P. Piecuch, A. Rehaman Moughal Shahi, L. Gagliard, J. Chem. Phys. A 2008, 112, 3754.

xvii A. D. Becke, K. E. Edgecombe, J. Chem. Phys. 1990, 92, 5397

xviii B. Silvi, A. Savin. Nature 1994, 371, 683

xix J.-P. Piquemal, et al. Int. J. Quant. Chem 2008, 108, 1951

${ }^{x x}$ P. E. M. Siegbahn , M. Wirstam, J. Am. Chem. Soc., 2001, 123, 11819

xxi J-P. Piquemal, J. Pilmé, J. Mol. Struct: THEOCHEM, 2006, 764, 77

xxii A. de la Lande, D. R. Salahub, H. Gérard, V. Moliner, V., JP.Piquemal, O. Parisel, O. Inorg. Chem., 2009, 48, 7003

${ }^{x x i i i}$ P. Chen, E. I. Solomon, J Inorg Biochem, 2002, 88, 368.

xxiv M. Leboeuf, A. M. Köster, K. Jug, D. R. Salahub, J. Chem. Phys.1999, 111, 4893

xxv A. Scemama, P. Chaquin, M. Caffarel, J. Chem. Phys., 2004, 121, 1725

xxvi These methods, and especially the latter one, require huge computational resources and have been only applied to the $\mathrm{Cu}_{2} \mathrm{O}_{2}$ complex.

xxvii $\quad$ Q. Wu, T. Van Voorhis, Phys. Rev. A, 2005, 72, 024592

xxviii A. de la Lande, D. R. Salahub , J. Mol. Struct. (THEOCHEM), 2010, 943, 115.

${ }^{\text {xxix }}$ A. de la Lande, J. Maddaluno, O. Parisel and J.-.P. Piquemal, Interdiscip.

Sci. Comput. Life Sc., 2010, 2, 3

xxx H. Decker, T. Schweikardt, F. Tuczek, Angew. Chem. Int. Ed. 2006, 45, 4546.

xxxi Bauman, A.T., Yukl, E. T., Q Alkevich, K., McCormack, A. L., Blackburn, N. J. J. Biol. Chem. 2006, 281, 4190.

xxxii A. de la Lande, H. Gérard, O. Parisel,Int. J. Quant. Chem., 2008, 108, 1898.

xxxiii The exact nature of the transferred group, i.e. $\mathrm{H}$ or $\mathrm{H}^{-}$, is still under debate for non coupled copper monooxygenases.

xxxiv S. T. Prigge, R. E. Mains, B. A. Eipper, L. M Amzel, Cell Mol. Life Sci. 2000, 57, 1236.

xxxv S. T. Prigge, B. A. Eipper, R. E. Mains, L. M. Amzel, Science, 2004, 304, 864

xxxvi P. E. M. Siegbahn, F. Haeffner, J. Am. Chem. Soc., 2004, 126, 8919.

xxxvii $\quad$ T. C. Bruice, Chem. Rev., 2006, 106, 3119.

xxxviii S. Martí, M. Roca, J. Andrés, V. Moliner, E. Silla E, I. Tuñón, J.

Bertrán, Chem. Soc. Rev. 2004, 33, 98. 
Aurélien de la Lande,* Dennis R. Salahub,

Jacques Maddaluno, Anthony

Scemama, Julien Pilmé,

Olivier Parisel, Hélène Gérard,

Michel

Caffarel

and

Jean-Philip Piquemal*

Page - Page

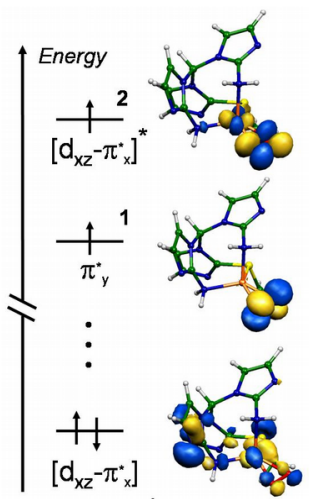

MOs resulting from the interaction between the dioxygen $\pi_{x}^{*}$ and $\pi_{y}^{*}$ molecular orbitals and the copper $d_{x z}$ orbital for the case of the $\left[\left(\mathrm{Mim}^{\mathrm{N} 2 \mathrm{~S}}\right) \mathrm{Cu}\left(\mathrm{O}_{2}\right)\right]^{+} \quad$ complex. Right: evolution of the average $\mathrm{CuO}_{1} \mathrm{O}_{2} \mathrm{~V}(\mathrm{O})_{1 / 3}$ dihedral angles as a function of the spin density at the $\mathrm{CuO}_{2}$ core upon progressive injection of one electron (constrained DFT computations) at a frozen geometry.

(Title Text)) 